\title{
Donation after brain circulation determination of death
}

\author{
Anne L. Dalle Ave ${ }^{1^{*}}$ and James L. Bernat ${ }^{2}$
}

\begin{abstract}
Background: The fundamental determinant of death in donation after circulatory determination of death is the cessation of brain circulation and function. We therefore propose the term donation after brain circulation determination of death [DBCDD].

Results: In DBCDD, death is determined when the cessation of circulatory function is permanent but before it is irreversible, consistent with medical standards of death determination outside the context of organ donation. Safeguards to prevent error include that: 1] the possibility of auto-resuscitation has elapsed; 2] no brain circulation may resume after the determination of death; 3] complete circulatory cessation is verified; and 4] the cessation of brain function is permanent and complete. Death should be determined by the confirmation of the cessation of systemic circulation; the use of brain death tests is invalid and unnecessary.

Because this concept differs from current standards, consensus should be sought among stakeholders. The patient or surrogate should provide informed consent for organ donation by understanding the basis of the declaration of death.
\end{abstract}

Conclusion: In cases of circulatory cessation, such as occurs in DBCDD, death can be defined as the permanent cessation of brain functions, determined by the permanent cessation of brain circulation.

Keywords: Transplantation, Ethics, Donation after circulatory determination of death [DCDD], Extracorporeal membrane oxygenation [ECMO], Brain criterion of death, Determination of death

\section{Background}

Human death has been conceptualized traditionally as a unitary phenomenon characterized by the irreversible cessation of the three vital functions: respiration, circulation and brain function [1]. Advances in life-sustaining therapies have disrupted the unitary nature of death, because now, new technologies can support or restore some vital functions while others remain absent [2]. The development of mechanical ventilation in the 1950s permitted the maintenance of respiratory and, thereby, circulatory functions, despite the irreversible cessation of brain function [3]. That the three vital functions no longer are interdependent stimulated the development of the brain criterion of death [4].

Advances in resuscitation techniques, particularly cardiopulmonary resuscitation (CPR) and extracorporeal membrane oxygenation (ECMO)-assisted CPR [5-7]

\footnotetext{
* Correspondence: Anne.Dalle-Ave@chuv.ch

${ }^{1}$ Ethics Unit, University hospital of Lausanne, Rue du Bugnon 21, 1011

Lausanne, Switzerland

Full list of author information is available at the end of the article
}

now allow recovery of patients formerly considered dead. In donation after circulatory determination of death (DCDD) programs, because of the need to optimize organ suitability for donation, death is declared shortly after circulatory cessation [8], a time which has provoked questions over the validity of death determination [9-13].

Novel resuscitation techniques and DCDD have shown the need for a more explicit analysis of death by raising several controversial questions. Is the DCDD patient actually dead at the moment death is pronounced given that the cessation of circulation may not be irreversible at that time? Is reliance on the permanent cessation of circulation sufficient grounds to declare death? [14] How are the phenomena of circulatory cessation and brain cessation related as criteria of death? Which criterion should be used to determine death in the context of DCDD programs: the circulatory criterion, as practiced in the U.S. [15], the brain criterion [16] as practiced in Switzerland [17], the Netherlands [18], and other 
European countries, or both? And how in ideal practice should death be determined?

We address these questions in this article and conclude that the permanent cessation of brain circulation is the critical element underlying both the circulatory and brain determination of death. We therefore propose a new term of this concept: organ donation after brain circulation determination of death (DBCDD).

\section{The fundamental criterion of death is the cessation of brain function}

While the three vital functions (respiration, circulation and brain function) are interrelated and interdependent in the absence of medical intervention, the fundamental determinant of death is the irreversible cessation of brain function [19-21]. This state is achieved commonly by one of two pathways: (1) the permanent cessation of systemic (including brain) circulation after circulatory arrest; and (2) the cessation of brain circulation resulting from markedly increased intracranial pressure following a catastrophic brain injury [22].

Through the pathway of catastrophic brain injury, death is determined by the brain criterion of death, i.e. by the irreversible cessation of all clinical brain functions, including the brainstem $[4,23]$, while respiratory and circulatory functions remain sustained by mechanical ventilation. Through the pathway of circulatory cessation, the fundamental criterion of death is also the brain criterion. As a consequence of the cessation of systemic circulation, brain circulation ceases followed rapidly by a progressive neuronal destruction due to hypoxemia and ischemia [2], leading to the irreversible cessation of all brain function.

We offer two examples showing that, through the pathway of circulatory cessation, the bodily circulation most relevant to death determination is that to the brain. In the first example, a patient with cessation of systemic circulation has her brain circulation sustained by local ECMO. Her brain function remains intact because of the ongoing brain circulation, while her bodily circulation has otherwise ceased. The usual circulatory criterion of death, i.e. the cessation of systemic circulation, would declare this patient dead, despite the fact that she might be fully conscious.

In the second example, a DCDD donor has her systemic circulation sustained by ECMO, while brain circulation is blocked by either an inflated aortic occlusion balloon [24] or an aortic occlusive clamp [25]. Depending on the degree to which the balloon or the clamp excludes brain perfusion, the DCDD donor may be either dead or alive [26, 27]. These two examples show that, in the pathway of circulatory cessation, the relevant circulation in the determination of death is that to the brain.

\section{From irreversibility to permanency in the determination of death}

Philosophical and biological concepts of death require irreversibility. Irreversibility means that, once circulation and respiration have ceased, they cannot restart spontaneously and cannot be restored by any available technologies [28]. Yet, the medical determination of death using the circulatory/respiratory criterion relies on the permanent cessation of respiration and circulation. Permanent means that the ceased functions will not recover because they will not restart spontaneously and no medical attempts will be made to restart them. Therefore, a noncongruence exists between the concept of death that requires an irreversible cessation of vital functions and the medical standard of death determination that requires only their permanent cessation [28].

In the context of donation after brain determination of death (DBDD), brain death is declared only once physicians have established the irreversible cessation of brain function [23]. Irreversibility depends on the fact that, despite advances in brain resuscitation [29], no available technology can restore brain function once death has been confirmed by brain death tests [23]. Brain death has traditionally been formulated as a retrospective determination that shows that all clinical brain functions have ceased.

In the context of circulatory cessation (including DBCDD), irreversibility is, at least to some extent, contingent on physician action or inaction [30]. Apart from scenarios in which irreversibility is obvious clinically (eg, decapitation, incineration, decomposition, and rigor mortis), physicians declare death before a state of irreversibility has been achieved. It is common, particularly in the intensive care setting, to determine death only a few minutes after circulation ceases [31].

The exact duration of complete circulatory cessation necessary to achieve the irreversible cessation of brain function remains unknown [22]. Outcome studies after cardiac arrest reveal that some brain functions can be restored by resuscitation maneuvers after as long as 20 [32] to $30 \mathrm{~min}$ [33] of no-flow, i.e. from the time from collapse to the initiation of CPR [16]. Animal studies show that some brain functions may be restored after as long as $60 \mathrm{~min}$ of circulatory cessation [34-36].

These data suggest that, in DBCDD programs, the no-touch period - i.e. the time from circulatory cessation to the declaration of death which is usually 220 min [19, 37-39] - is too short to have achieved an irreversible cessation of neuronal function necessary to determine brain death. Furthermore, new technologies such as ECMO are able to restore some brain functions after approximately $30 \mathrm{~min}$ of circulatory cessation. Thus, in the context of circulatory cessation (including DBCDD), death is often determined during a state of permanent cessation but before a state of irreversible cessation [14]. 
Apart from the DBCDD context, physicians' usual determination of death using permanent cessation is justified when several conditions are fulfilled: 1) The possibility of auto-resuscitation has elapsed; 2) No action will be initiated to restore circulation after the determination of death; 3) Further elapsed time will permit confirming the certainty of death; 4) There are social reasons for physicians to declare death sooner rather than later; and 5) Brain function has permanently and completely ceased. Let us now analyze whether these justifications in nondonation settings are sufficient grounds to declare death before irreversibility in the DBCDD context.

1) The possibility of auto-resuscitation has elapsed Auto-resuscitation refers to the spontaneous return of heartbeat and circulation after asystole [2]. To avoid the possibility of a patient's revival after having been declared dead, death cannot be declared until the possibility of auto-resuscitation has elapsed. The minimal no-touch period to wait to ensure the impossibility of auto-resuscitation is unknown [40]. In one comprehensive retrospective study of withdrawal of life-sustaining therapy, the investigators found not a single case of autoresuscitation to restored circulation [41]. An observational study showed that 'the longest period of cessation of arterial blood pressure before resumption was $89 \mathrm{sec}$ [40]. While cardiac electrical activity persisted in some patients for more than $30 \mathrm{~min}$ after cardiac arrest, the authors concurred that 'true autoresuscitation required the spontaneous return of circulation' and not merely the return of cardiac electrical activity [2, 39-41]. By contrast, after failed CPR in the setting of unexpected cardiac arrest, auto-resuscitation to circulation remains possible after $7 \mathrm{~min}$ of cardiac arrest [41]. Available data suggest that in controlled DCDD following withdrawal of life-sustaining therapy, a no-touch period of $5 \mathrm{~min}$ is sufficient to ensure the impossibility of auto-resuscitation. But in uncontrolled DCDD after failed resuscitative efforts in an unexpected cardiac arrest, a no-touch period for as long as 10 min may be necessary [42].

2) No action will be initiated to restore circulation after the determination of death

Because after circulatory cessation, death usually is declared before the cessation of brain functions become irreversible, brain functions potentially could respond to the restoration of brain circulation [43]. To avoid this risk, the use of any procedures or technologies that can restore brain circulation should be avoided following the determination of death [19, 26, 43, 44]. DBCDD programs should avoid the use of post-mortem ECMO, as currently practiced in some controlled DBCDD programs $[24,25,45-47]$ and several uncontrolled DBCDD programs $[48,49]$. The post-mortem use of ECMO may retroactively invalidate the preceding death declaration by negating the necessary condition of permanent cessation of circulation. Similarly, the use of CPR after the declaration of death, as practiced in some uncontrolled DBCDD programs $[48,49]$, should be avoided, because it may restore brain circulation. Inflation of the lungs after the declaration of death, which some transplantation programs use when the lungs are planned to be procured, should be avoided, because it may stimulate the return of spontaneous heartbeat and circulation. Our current resuscitative technology has complicated the concept of irreversibility which now may be contingent on physician action or inaction [28].

\section{The case of cold organ preservation solution ECMO}

The University of Pittsburgh Medical Center is developing an innovative uncontrolled DCDD protocol using post-mortem ECMO with cold organ preservation solution instead of blood to preserve organs [50]. In their protocol, brain perfusion is resumed after the declaration of death not with blood but with cold fluid. Although the cold solution cannot oxygenate the brain, the accompanying hypothermia slows brain neuronal metabolism. Hypothermia could invalidate the preceding determination of death by preventing the brain neuronal hypoxic-ischemic damage that allows death to be determined on the grounds of the permanent cessation of circulation. We therefore recommend avoiding the use of cold organ preservation solution ECMO.

3) Further elapsed time will permit confirming the certainty of death One controversy in declaring death prior to a state of irreversibility in DBCDD is that, because organ procurement rapidly follows the determination of death, the ability to confirm the certainty of death is diminished [10]. Because death in DBCDD is followed by organ procurement, the diagnosis of death must be certain [13].

In DBDD, irreversibility is necessary to diagnose death, because of the ongoing circulation and the risk of confounded and reversible conditions that may mimic brain death [23]. In DBCDD, irreversibility is unnecessary to the diagnosis of death because the permanent cessation of circulation will always lead to the irreversible cessation of brain function. The risk of error in the determination of death in the context of circulatory 
cessation results only from whether circulatory cessation is total and whether the possibility of auto-resuscitation has elapsed.

Because in the DBCDD context, the cessation of circulation must be total, a technique such as intra-arterial monitoring, Doppler flow study, or echocardiography showing the non-opening of the aortic valve should be required to confidently distinguish the complete absence of circulation from the presence of small degree of circulation [20].

4) There are social reasons for physicians to declare death sooner than later

In cases of circulatory cessation, physicians have declared death prior to the moment of irreversibility for social reasons without creating controversy. Delaying the declaration of death for a few hours while awaiting clinical signs of irreversibility (lividity, rigidity), imposes unjustifiable harms on family members. Interference with the bereavement process and preparation of the body caused by the delay in the determination of death may produce emotional and psychological suffering. It was not until DBCDD standards of death determination had to be made explicit that any controversy arose. We believe that the social reasons to declare death prior to irreversibility also apply in the DBCDD context. Because the declaration of death is more consequential in the DBCDD context, there should be safeguards to assure that: 1) the possibility of auto-resuscitation has elapsed; 2) circulatory cessation is total; 3) no actions will be initiated after the declaration of death that may possibly resume brain circulation and/or function; and 4) brain functions must have ceased permanently and completely.

5) Brain functions have permanently and completely ceased

One worry raised by critics of relying on permanent cessation to declare death in DBCDD is that the donor may suffer because organ procurement will happen before the state of brain function irreversibility [51]. These critics claim that whereas, a "premature" declaration of death may be inconsequential outside the DBCDD context, it is very consequential in DBCDD, because bodily integrity may be damaged by organ procurement. To avoid any risks of inducing suffering on DBCDD donors by surgical procedures [52], we must be certain that the declaration of death corresponds to the cessation of all brain functions, thereby excluding the possibility of feeling pain and awareness.

The precise time interval after brain circulatory cessation necessary to ensure the complete cessation of brain function is unknown. There is a consensus among neuroscientists and neurologists that brain function is a necessary condition of awareness, and that normothermic patients who have completely lost systemic (and therefore brain) circulation for more than a few minutes have no brain function or awareness. Brain circulatory cessation for $5 \mathrm{~min}$ at normothermia thus ensures the permanent and complete cessation of all brain functions. This condition, in turn, ensures that the DBCDD donor cannot experience any pain, suffering or awareness. The clinical assessment of the absence of brain function in the context of circulatory cessation cannot be accomplished easily. Surface electroencephalogram (EEG) examination may show the absence of thalamocortical electrical activity, but cannot exclude residual activity within brain stem structures $[10,19,51]$. In a case series of bispectral (BIS) measurements during DBCDD, the BIS value fell quasi-instantly to zero after cardiac arrest [53]. In the observational study done by Dhanani et al., EEG activity stopped rapidly after circulatory cessation but persisted for $26 \mathrm{~min}$ in one patient. The authors concluded that the measured EEG activity in that case was artifact [40]. A recent literature review revealed that most analyzed studies showed the absence of consciousness and EEG activity within $30 \mathrm{~s}$ of circulatory cessation [54]. The confirmation of the precise period of time necessary to achieve the permanent and complete cessation of brain function after circulatory cessation must be further studied. In the meantime, a no-touch period of 5 min seems sufficient to achieve the permanent and complete cessation of all brain functions.

\section{How is death determined in DBCDD?}

In the context of circulatory cessation, death is determined by the confirmation of the cessation of circulation and respiration. In the context of DBCDD, the complete cessation of systemic circulation should be confirmed with certainty by the use of an arterial line, a Doppler, or an echocardiogram.

If any technologies or procedures are used that possibly could resume brain circulation after death declaration, it must be proven that brain circulation has been completely excluded [26]. However, there may be technical difficulties in interpreting brain blood flow studies to prove the complete absence of brain circulation, particularly in distinguishing zero blood flow from a very small amount of blood flow.

The use of accepted and validated brain death test batteries in the context of DBCDD is inapplicable and unnecessary [16]. In DBDD, brain death tests are valid only if reversible causes of brain function cessation have 
been excluded, which is unfeasible in DBCDD, as we have discussed elsewhere [16].

Furthermore, because systemic circulatory cessation will automatically cause brain circulation to cease, which will lead to the progressive destruction of neuronal tissue, it is unnecessary to use brain death tests in the context of DBCDD. The confirmation of the permanent absence of systemic circulation is thus sufficient to determine death. To ensure that the possibility of autoresuscitation has elapsed, death should be declared only after at least $5 \mathrm{~min}$ of no-touch period in controlled DBCDD and 10 min in uncontrolled DBCDD.

\section{Conclusion}

When systemic circulation ceases, the criterion of death is the permanent cessation of brain circulation. When organ donation is conducted, we call it donation after brain circulation determination of death or DBCDD. The brain circulation criterion of death becomes valid once six conditions are fulfilled as listed in Table 1.

Our proposal departs from medical standards of brain death in which the retrospective irreversible cessation of brain function has been a longstanding requirement. This prospective determination of permanent cessation of brain circulation and function is sufficient to declare that the DBCDD donor is dead. Our proposal has the advantage of unifying the phenomenon of death under the single brain criterion of death for both common pathways: circulatory cessation and primary brain damage.

Table 1 The conditions of validity of the brain criterion of death in the context of DBCDD

\begin{tabular}{|c|c|}
\hline & Conditions of validity \\
\hline \multirow[t]{2}{*}{ 1] } & The possibility of autoresuscitation has elapsed: \\
\hline & $\begin{array}{l}\text { - no-touch period of } 5 \mathrm{~min} \text { in controlled DBCDD } \\
\text { - no-touch period of } 10 \mathrm{~min} \text { in uncontrolled DBCDD }\end{array}$ \\
\hline \multirow[t]{2}{*}{ 2] } & $\begin{array}{l}\text { No interventions that may resume brain circulation } \\
\text { after the determination of death will be performed: }\end{array}$ \\
\hline & $\begin{array}{l}\text { - no CPR - no ECMO, unless the brain circulation } \\
\text { is proven to have been securely excluded } \\
\text { - no lung inflation }\end{array}$ \\
\hline \multirow[t]{2}{*}{ 3] } & $\begin{array}{l}\text { The diagnostic of cessation of brain circulation is } \\
\text { certain using at least one test: }\end{array}$ \\
\hline & $\begin{array}{l}\text { flat arterial line } \\
\text { - no arterial Doppler signal } \\
\text { - no opening of the aortic valve on echocardiography }\end{array}$ \\
\hline \multirow[t]{2}{*}{ 4] } & $\begin{array}{l}\text { There is a permanent and complete cessation of } \\
\text { all brain functions: }\end{array}$ \\
\hline & - a minimal no-touch period of $5 \mathrm{~min}$ is required \\
\hline 5] & $\begin{array}{l}\text { There is consensus that the determination of death } \\
\text { may be based on the permanent cessation of brain } \\
\text { circulation and function }\end{array}$ \\
\hline 6] & Informed consent for DBCDD has been obtained \\
\hline
\end{tabular}

Death could thus be defined as the permanent cessation of brain functions, determined either by the permanent cessation of brain circulation in cases of circulatory cessation (including to the brain) or by the irreversible cessation of brain functions in cases of severe brain injury.

\section{Abbreviations}

CPR: Cardio-pulmonary resuscitation; DBCDD: Donation after brain circulation determination of death; DBDD: Donation after brain determination of death; DCDD: Donation after circulatory determination of death;

ECMO: Extracorporeal membrane oxygenation

\section{Acknowledgements}

None.

Funding

None.

Availability of data and materials

Not applicable.

\section{Authors' contributions}

ADA wrote the first draft after several exchanges of discussions with JLB in order to build the argument. JLB worked with ADA to develop the lines of argument of the article, and edited and rewrote sections of the article during an iterative series of drafts. Both authors take responsibility for the arguments presented in the article. Both authors read and approved the final manuscript.

\section{Competing interests}

The authors declare that they have no competing interests.

\section{Consent for publication}

Not applicable.

Ethics approval and consent to participate

Not applicable.

\section{Author details}

${ }^{1}$ Ethics Unit, University hospital of Lausanne, Rue du Bugnon 21, 1011 Lausanne, Switzerland. ${ }^{2}$ Neurology Department, Dartmouth-Hitchcock Medical Center, Lebanon, NH 03756, USA.

Received: 25 August 2016 Accepted: 3 February 2017

Published online: 23 February 2017

\section{References}

1. Eisenberg M. S., Baskett P., Chamberlain D. A history of cardiopulmonary resuscitation. In: Cardiac arrest: The science and practice of resuscitation in medicine. Paradis N. et al. Cambridge: Cambridge University Press; 2007.

2. Bernat JL. Controversies in defining and determining death in critical care. Nat Rev Neurol. 2013;9:164-73.

3. Kacmarek M. The mechanical ventilator: past, present, and future. Respir Care. 2011;56(8):1170-80.

4. Report of the ad hoc committee of the Harvard medical school to examine the definition of brain death. A definition of irreversible coma JAMA. 1968; 20: 6; 86-88

5. Stub D, Bernard S, Pellegrino V, et al. Refractory cardiac arrest treated with mechanical CPR, hypothermia, ECMO and early reperfusion [the CHEER trial]. Resuscitation. 2015;86:88-94.

6. Sakamoto T, Morimura N, Nagao K, et al. Extracorporeal cardiopulmonary resuscitation versus conventional cardiopulmonary resuscitation in adults with out-of-hospital cardiac arrest: a prospective observational study. Resuscitation. 2014;85:762-8.

7. Mueller PS, Hook CC. Technological and treatment imperatives, lifesustaining technologies, and associated ethical and social challenges. Mayo Clin Proc. 2013;88:641-4

8. Gardiner D, Shemie S, Manara A, Opdam H. International perspective on the diagnosis of death. Br J Anaesth. 2012;108 suppl 1:14-28.

9. Rady MY, Verheijde JL. No-touch time in donors after cardiac death [nonheartbeating organ donation]. Curr Opin Organ Transplant. 2013;18:140-7. 
10. Joffe AR, Carcillo J, et al. Donation after cardiocirculatory death: a call for a moratorium pending full public disclosure and fully informed consent. Philos Ethics Humanit Med. 2011;6:17. www.peh-med.com/content/6/1/17.

11. Potts M. Truthfulness in transplantation: non-heart-beating organ donation. Philos Ethics Humanit Med. 2007;2:17. doi:10.1186/1747-5341-2-17.

12. Marquis D, Are DCD. Donors dead? Hastings Cent Rep. 2010;40(3):24-31.

13. Miller FG, Truog RD. Rethinking the ethics of vital organ donations. Hastings Cent Rep. 2008;38(6):38-46

14. Bernat JL. How the distinction between 'irreversible' and 'permanent' illuminates circulatory-respiratory death determination. J Med Philos. 2010;35:242-55.

15. Uniform Determination of Death Act, 12 uniform laws annotated 589 [West 1993 and West suppl 1997]

16. Dalle Ave $A L$, Bernat $J$. Using the brain criterion in organ donation after the circulatory determination of death. J Crit Care. 2016;33:114-8.

17. Swiss Federal Act on Transplantation of Organs, Tissues and Cells. 8th October 2004 [SR 810.21].

18. Law on Organ Donation, Article 14(2). http://wetten.overheid.nl/ BWBR0008066/2016-08-01. Assessed in January 2017.

19. Shemie SD, et al. National recommendations for donation after cardiocirculatory death in Canada. CMAJ. 2006;175 suppl 8:S1-24.

20. Bernat $\mathrm{J}$, Capron AM, Black TP, et al. The circulatory-respiratory determination of death in organ donation. Crit Care Med. 2010;38:963-70.

21. Ridley S, Bonner S, Bray K, et al. UK guidance for non-heart-beating donation. Br J Anaesth. 2005;95(5):592-5.

22. Shemie SD, Hornby L, Baker A, Teitelbaum J, Torrance S, Young K, et al. International guideline development for the determination of death. Intensive Care Med. 2014;40:788-97.

23. Wijdicks EFM, Varelas PN, Gronseth GS, Greer DM. Evidence-based quideline update: determining brain death in adults. Report of the quality standards subcommittee of the American academy of neurology. Neurology. 2010;74:1911-8.

24. Rojas-Peňa A, Sall LE, Gravel MT, et al. Donation after circulatory determination of death : the University of Michigan experience with extracorporeal support. Transplantation. 2014;98(3):328-34.

25. Ali A, White $P$, Dhital $K$, Ryan $M$, Tsui S, Large $S$. Cardiac recovery in a human non-heart-beating donor after extracorporeal perfusion: source for human heart donation? J Heart Lung Transplant. 2009;28(3):290-3.

26. Dalle Ave AL, Shaw DM, Bernat JL. Ethical issues in the use of extracorporeal membrane oxygenation in controlled donation after circulatory determination of death. A J Transplantation. 2016;16(8):2293-9.

27. Dalle Ave AL, Shaw D, Bernat JL. An analysis of heart donation after circulatory determination of death. J Med Ethics. 2016:42(5):312-7. doi:10.1136/medethics-2015-103224.

28. Bernat JL. On noncongruence between the concept and determination of death. Hastings Cent Rep. 2013;43(6):25-33.

29. Knapton S. Dead could be brought 'back to life' in groundbreaking project. The telegraph. 3rd ed. 2016. http://www.telegraph.co.uk/science/2016/05/ 03/dead-could-be-brought-back-to-life-in-groundbreaking-project.

30. Parnia S. Death and consciousness - an overview of the mental and cognitive experience of death. Ann NY Acad Sci. 2014;1330:75-93.

31. Wind J., Van Mook W. N.K.A., Dhanani S., Van Heurn E. Determination of death after circulatory arrest by intensive care physicians. A survey of current practice in the Netherlands. J Crit Care 2015. 10.1016/j.jcrc.2015.09.006

32. Testori C, Sterz F, Holzer M, et al. The beneficial effect of mild therapeutic hypothermia depends on the time of complete circulatory standstill in patients with cardiac arrest. Resuscitation. 2012;83:596-601.

33. Hara M, Hayashi K, Hikoso S, et al. Different impacts of time from collapse to first cardiopulmonary resuscitation on outcomes after witnessed out-ofhospital cardiac arrest in adults. Circ Cardiovas Qual Outcomes. 2015;8(3): 277-84. doi:10.1161/CIRCOUTCOMES.115.001864

34. Hossmann KA, Schmidt-Kastner R, Grosse OB. Recovery of intergrative central nervous function after one hour global cerebro-circulatory arrest in normothermic cat. J Neurol Sci. 1987:77(2-3):305-20.

35. Weihs W, Krizanac D, Sterz F, et al. Rapid induction of hypothermia with a small volume aortic flush during cardiac arrest in pigs. Am J Emerg Med. 2012;30:643-50.

36. Hossmann KA, Grosse Ophoff B. Recovery of monkey brain after prolonged ischemia. 1. Electrophysiology and brain electrolytes. J Cereb Blood Flow Metab. 1986;6:15-21.
37. Dhanani S, Hornby L, Ward R, Shemie S. Variability in the determination of death after cardiac arrest: a review of guidelines and statements. J Intensive Care Med. 2012;27(4):238-52

38. Ethics Committee, American College of Critical Care Medicine and Society of Critical Medicine. Recommendations for non-heartbeating organ donation. A position paper by the ethics committee, American college of critical care medicine, society of critical care medicine. Crit Care Med. 2001;29:1826-31.

39. Bernat JL, et al. Report of a national conference on donation after cardiac death. Am J Transplant. 2006;6:281-91.

40. Dhanani S, Hornby L, Ward R, Baker A, Dodek P, Chamber-Evans J, et al. Vital signs after cardiac arrest following withdrawal of life-sustaining therapy: a multicenter prospective observational study. Crit Care Med. 2014;42(11):2358-69.

41. Hornby K, Hornby L, Shemie SD. A systematic review of autoresuscitation after cardiac arrest. Crit Care Med. 2010;38(5):1246-53.

42. Bernat JL. How auto-resuscitation impacts death determinations in organ donors. Crit Care Med. 2010;38:1377-8.

43. Manara AR, Murphy PG, O'Callaghan G. Donation after circulatory death. Br J Anaesth. 2012;108 suppl 1:i108-21.

44. Bernat $J$. The boundaries of organ donation after circulatory death N Engl J Med. 2008;359:669-71.

45. Henry Ford Hospital -Detroit Campus; Administrative and Clinical manual Organ donation after cardiac death. 2009. http://www.organdonation alliance.org/wp-content/uploads/toolbox/DCDHospitalPolicy-HenryFord HealthSystem-odt.pdf

46. Farney $\mathrm{AC}$, Hines $\mathrm{MH}$, et al. Lessons learned from a single center's experience with 134 donation after cardiac death donor kidney transplants. J Am Coll Surg. 2011;212(4):440-51.

47. Oniscu GC, Randle LV, Muiesan P, et al. In situ normothermic regional perfusion for controlled donation after circulatory death- the United Kingdom Experience. Am J Transplant. 2014;14:2846-54.

48. Abboud I, Viglietti $D$, et al. Preliminary results of transplantation with kidneys donated after cardiocirculatory determination of death: a French single-center experience. Nephrol Dial Transplant. 2012;27:1583-2587.

49. Mateos-Rodríguez A, Pardillos-Ferrer L, Navalpotro-Pascual JM, et al. Kidney transplant function using organs from non-heart-beating donors maintained by mechanical chest compressions. Resuscitation. 2010;81(7): 904-7. doi:10.1016/j.resuscitation.2010.04.024.

50. DeVita MA, Callaway CW, Pacella C, Brooks MM, Lutz J, Stuart S. Experience with a New process - condition $T$ - for uncontrolled donation after circulatory determination of death in a university emergency department. Prog Transplant. 2016;26(1):21-7. doi:10.1177/1526924816632117.

51. Rady MY, et al. Neuroscience and awareness in the dying human brain: implication for organ donation practices. J Crit Care. 2016:34:121-3.

52. Rady MY, Verheijde JL, McGregor JL. Scientific, legal, and ethical challenges of end-of-life procurement in emergency medicine. Resuscitation. 2010;81:1069-78.

53. Auyong DB, Klein SM, Gan TJ, Roche AM, Olson D, Habib AS. Processed electroencephalogram during donation after cardiac death. Anesth Analg. 2010;110(5):1428-32

54. Pana R, Hornby L, Shemie SD, Dhanani S, Teitelbaum J. Time to loss of brain function and activity during circulatory arrest. J Crit Care. 2016;34:77-83.

\section{Submit your next manuscript to BioMed Central and we will help you at every step:}

- We accept pre-submission inquiries

- Our selector tool helps you to find the most relevant journal

- We provide round the clock customer support

- Convenient online submission

- Thorough peer review

- Inclusion in PubMed and all major indexing services

- Maximum visibility for your research

Submit your manuscript at www.biomedcentral.com/submit 